\title{
ANALISE PARA TOMBAMENTO - INVENTÁRIO DE BENS CULTURAIS DA IGREJA MATRIZ SÃO JOÃO BATISTA DE PIRAPOZINHO.
}

\author{
Camila Le Bourlegat, Mariane Olivo, Fabrícia Dias da Cunha de Moraes Fernandes Borges \\ Universidade do Oeste Paulista - UNOESTE, Curso de Arquitetura e Urbanismo, Presidente Prudente, SP. E-mail: \\ fabricia.arquiteta@gmail.com
}

\begin{abstract}
RESUMO
As histórias são formuladas a partir de lembranças, objetos, edificações que pertenceram a uma determinada época e que para esse período foram importantes. Quando pensamos na história da cidade, esta é marcada por todos que ali viviam e por tudo o que eles construíram. Baseado na importância da história de uma sociedade e nas propostas de preservação e tombamento de edificações que remetem a memória de um povo é que neste artigo será feito um levantamento histórico da Igreja Matriz de Pirapozinho, relacionado a sua importância na vida e memória dos habitantes para o seu pedido de tombamento.

Palavras-chave: Patrimônio. Memória. Igreja Matriz. Pirapozinho.

\section{ANALYSIS FOR TIPPING - INVENTORY OF CULTURAL GOODS OF THE MOTHER CHURCH OF SÃO JOÃO BATISTA DE PIRAPOZINHO}

\begin{abstract}
The stories are made from memories, objects, buildings that belonged to a certain time and that for that period were important. When we think of the history of city, this is marked by all that lived there and for all that they build. Based on the importance of the history of a society and in the preservation proposals and tipping buildings that refer to the memory of a people and that this article will be, made a historical survey of the Church Pirapozinho matrix related your importance in the life and memory of the people for tipping his request.
\end{abstract}

Keywords: Equity, Memory, Church Matrix, Pirapozinho. 


\section{INTRODUÇÃO}

Os patrimônios são uma herança do passado, de uma época que não vai voltar. Eles são de grande importância para a história, para a arquitetura e para a nação, mas são importantes principalmente para as pessoas que habitam a região em que eles se encontram, através da memória coletiva e individual.

Segundo Martins (2011)

Património cultural é o conjunto de bens, materiais e imateriais, que são considerados de interesse coletivo, suficientemente relevantes para a perpetuação no tempo. O património faz recordar o passado; é uma manifestação, um testemunho, uma invocação, ou melhor, uma convocação do passado. Tem, portanto, a função de (re) memorar acontecimentos mais importantes; daí a relação com o conceito de memória social. A memória social legitima a identidade de um grupo, recorrendo, para isso, do património. (MARTINS, 2011, s/p)

A preservação de monumentos históricos assume significado essencial cultural, é estimo valor que a população local se importe com a história, tradição, assim como cita Hannah (1979),

Sem testamento, [...] ou sem tradição - que selecione ou nomeie, que transmita e preserve, que indique onde se encontram os tesouros e qual o seu valor -, parece não haver nenhuma continuidade consciente no tempo, e portanto, humanamente falando, nem passado nem futuro, mas tão somente a sempiterna mudança do mundo e ciclo biológico das criaturas que nele vivem. (ARENDT, 1979, p. 31)

Assim com o advento da Constituição Federal de 1988 o inventário foi finalmente alçado, em nosso país, a instrumento jurídico de preservação do patrimônio cultural, ao lado do tombamento, da desapropriação, dos registros, da vigilância e de outras formas de acautelamento e preservação (BRASIL. art. 216, § 1으, 1988).

Sob o ponto de vista prático o inventário consiste na identificação e registro por meio de pesquisa e levantamento das características e particularidades de determinado bem, adotando-se, para sua execução, critérios técnicos objetivos e fundamentados de natureza histórica, artística, arquitetônica, sociológica, paisagística e antropológica, entre outros.

Dentro desta discussão este artigo tem como objetivo tornar patrimônio cultural, através de Inventário de Bens Culturais, com tombamento a Igreja Matriz São João Batista de Pirapozinho, sendo esta tão importante à população local.

Nos relatos e artigos da cidade obtidos através da secretaria paroquial da igreja, não se encontra uma preocupação com a história, tradição e preservação local, essa falta de interesse pode ser por diversas razões, entre elas a falta de cultura e politicas aplicadas que conscientiza e 
informa a importância de muitas obras do passado que segue gerações como um acervo de memórias e histórias de seus antepassados. Assim devido esse descaso e descuido com a história de um povo é que muitas edificações são destruídas ou passam por modernizações que as descaracterizam completamente, apagando a memória que seguiria para gerações futuras. Com esses fatores, hoje políticas estão sendo desenvolvido, o aumento dos pedidos de tombamentos, as inserções desse assunto nas escolas como objeto de estudo, conscientizando as novas gerações valorizar e preservar estes patrimônios, para que estes possam fazer parte da vida das novas histórias que virão.

\section{METODOLOGIA}

A metodologia basea-se numa investigação bibliográfica e in loco que se fundamentará numa abordagem qualitativa de pesquisa, utilizando-se como instrumento um levantamento bibliográfico, documental e físico que segundo Teixeira (2000), busca a correlação entre a teoria e os dados, entre o contexto e a ação, a partir da compreensão dos fenômenos por meio de sua descrição e interpretação. Para o trabalho com o estudo do tipo de levantamento bibliográfico ocorrerá inicialmente um levantamento das principais produções no contexto nacional de estudos, considerando a peculiaridade do objeto de estudo.

Desse modo, percebe-se que a pesquisa qualitativa vale-se do método indutivo, segundo o qual parte da observação, da análise dos fatos particulares, dos registros para compor um quadro compreensivo para então constituir a generalização universal, ou seja, a teoria. O processo de indução vale-se do princípio do empirismo, no qual o conhecer é dar significado à realidade (KÖCHE, 1997).

\section{BREVE HISTÓRICO DA IGREJA MATRIZ SÃO JOÃO BATISTA DE PIRAPOZINHO}

Fundada no dia 19 de março de 1946, pelo Bispo Dom Antonio José dos Santos da Diocese de Assis, teve como primeiro Pároco Pe. Hilário Pierik, que exercia o cargo de Cura da Catedral de Assis, veio para tomar posse de Vigário de Pirapozinho no dia 5 de abril de 1946 numa acanhada igrejinha de madeira, sendo esta a primeira capela de Pirapozinho construída através de uma ação dos moradores, sendo concluída no dia 19 de março de1934, dois anos antes de a Lei garantir a categoria de distrito. A antiga capela em 1946, mesmo em situações precárias torna-se Paróquia. Em junho de 1946, com dois meses de paróquia inicia-se um trabalho junto à comunidade para a construção da Igreja Matriz, mostrado na figura 01. 


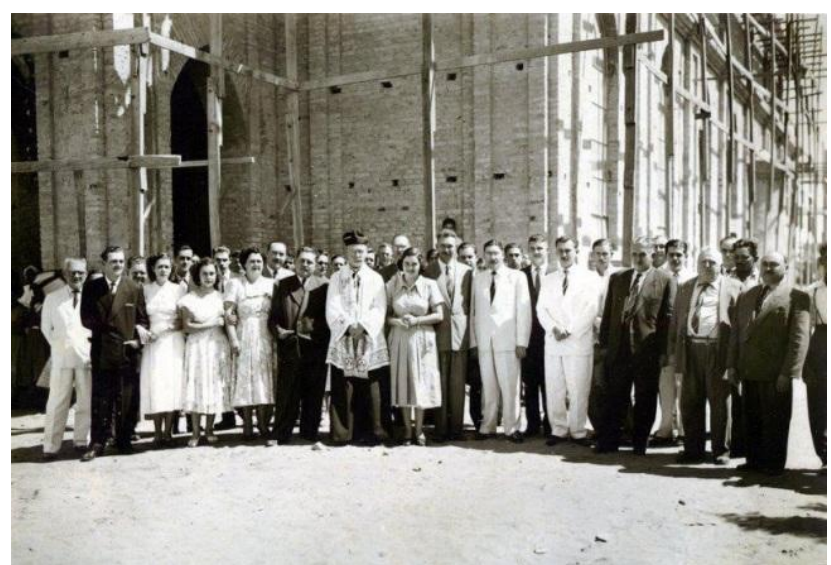

Figura 01. Construção da Matriz em 1946.

Fonte: Secretaria Paroquial

Enquanto se pensava na construção, foi construída no mês de julho de 1946 uma igreja provisória de madeira. No dia 06 de março de 1946 foi dada a solene benção da Pedra Fundamental da Igreja Matriz iniciando assim sua construção, sendo finalizada no fim de 1955, e ainda no mesmo ano antes do seu término foram instalados os sinos obtidos através de doações, sendo o maior doado pelo padre Hilário. Após oito anos de construída, em 1962 foi instalado o relógio, mostrado na figura 02. Em 1981 foi pintada externamente de verde.

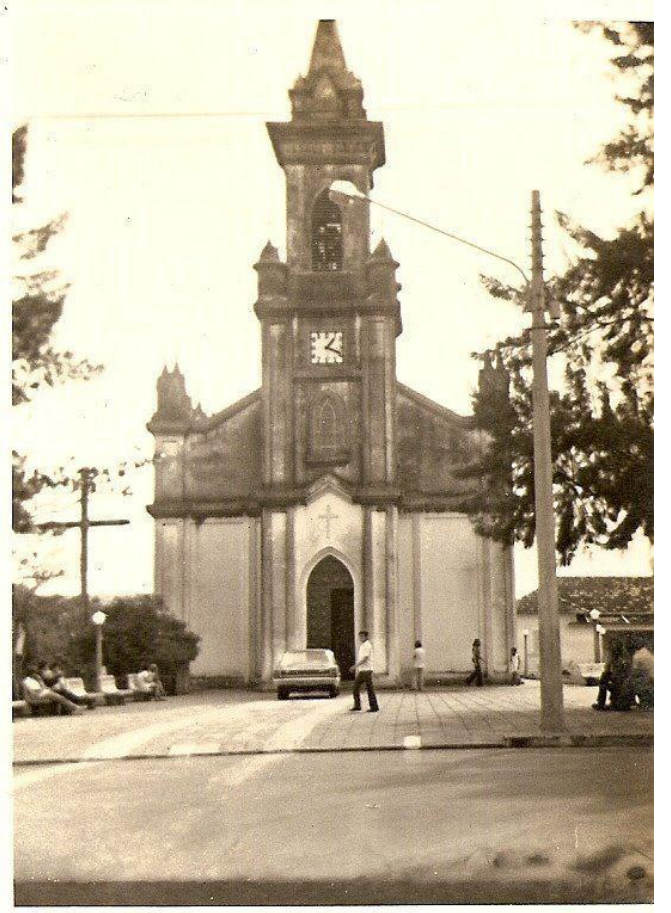

Figura 02. Inserção do relógio na fachada

Fonte: Secretaria Paroquial 
Com base em dados obtidos na secretária paroquial, Pirapozinho era em 1946, um pequeno distrito de paz dependente do Município de Presidente Prudente, com um número de habitantes que não passava de mil. Com o crescimento da população da cidade a igreja não suportava mais a quantidade de fiéis, assim no dia 09 de abril de 1997, inicia-se a ampliação e reforma da Igreja, que teve a sua capacidade aumentada para receber de 400 à 1500 fiéis sentados. Totalmente funcional e com um sistema de refrigeração que oferece grande conforto e comodidade aos fiéis, proporcionando bons momentos para a oração e recolhimento espiritual. Sua reinauguração ocorreu no dia 17 de dezembro de 2000.

A Igreja Matriz de Pirapozinho está localizada em uma praça no centro da cidade e como a maioria das igrejas antigas encontra-se em um local alto da cidade, podendo ser vista de vários ângulos da cidade, tornando-se assim um ponto de referência. Sua torre é relativamente alta, mostrado na figura 03, se destaca entre as demais construções já que Pirapozinho tem apenas um edifício localizado na parte mais baixa da cidade. Ao seu redor há bastante vegetação, entretanto, por estar em uma praça, não existe piso permeável e nem muitas árvores e arbustos. Não há ponto de ônibus perto, porém é um lugar de encontro e sua calçada é local de espera com bancos. Diferente da maioria das Catedrais que observamos em outras cidades não possui escadaria, sendo no nível da calçada.

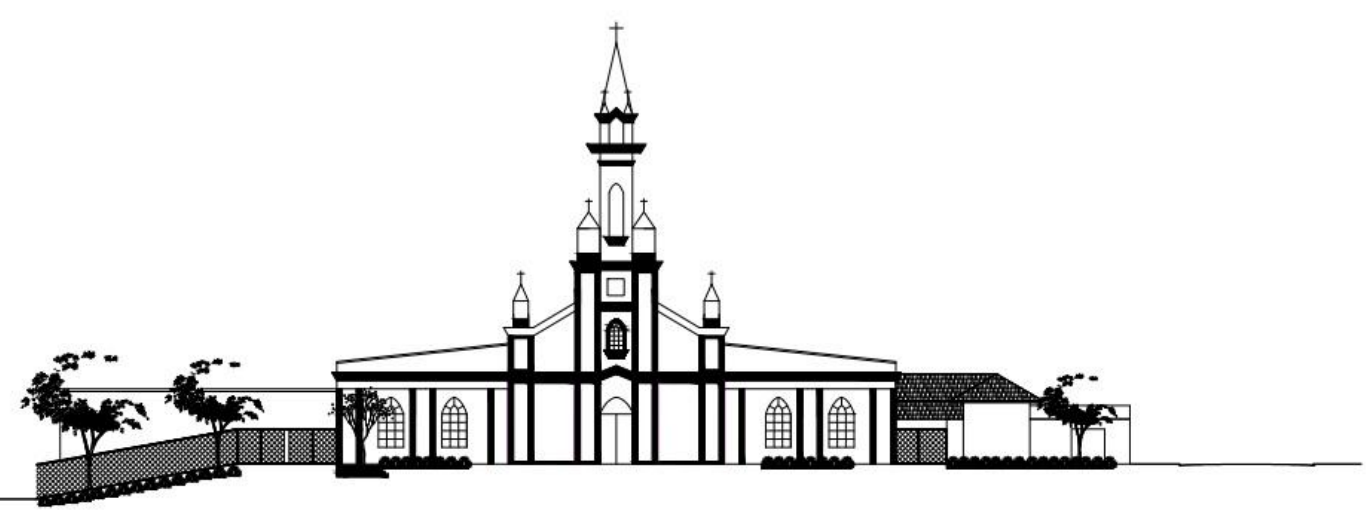

Figura 03. Fachada da Igreja Matriz

Fonte: Desenho equipe 2015

Com pesquisa in loco observou-se uma prática imaterial, como procissão e passagem de pedestres. Possui recuos frontal e laterais, feita de "tijolão"- tijolo antigo. Sua fachada não possui pilares nem colunas, porem existe um pouco de avanço e retrocesso. Também tem frisos relembrando o art'deco, internamente os pilares são revestidos até a metade de mármore. 0 Acesso Principal é pela fachada, sendo que o acesso ao público é direto sem portões e muros. No 
ano da construção em 1946 se constituía apenas por um volume único, tornando-se três volumes em 2000. Possui apenas um pavimento com pé direito duplo de 9 metros.

A edificação encontra-se em perfeitas condições. A pintura é recente, tanto o piso interno quanto a pavimentação externa estão em condições boas. Não foi encontrado nenhuma irregularidade na parte física da edificação, não há goteiras, nem perda de material, a estrutura está excelente, pois o prédio funciona normalmente e está aberto todos os dias para os fiéis, mostrado na figura 04.

A inserção dos sinos já no término da sua construção e do relógio anos posteriores, não descaracterizou a construção, pois a área em que seriam instalados já havia sido deixada na construção. Referente à inserção das duas naves laterais, houve uma descaracterização interna, pois para a ampliação teve de abrir as paredes laterais e retirando assim alguns ornamentos e aberturas existentes.

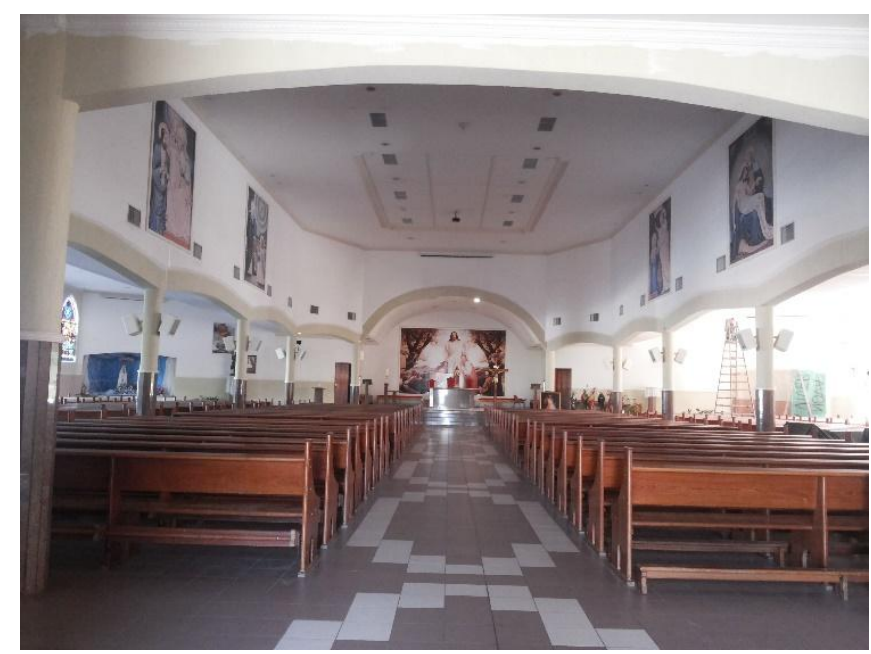

Figura 04. Interno da Igreja

Fonte: Equipe 2015

No altar foi ampliada a abertura existente para melhor visão dos fiéis no altar, e nas extremidades ainda do altar em sua parte posterior foi criado chanfros não existes, mostrado na figura 05. Quanto a parte externa da ampliação, não houve descaracterização da edificação, pois é visível a inserção daquela parte posteriormente, ainda que os ornamentos e formas da edificação antiga não foram copiado na nova. 


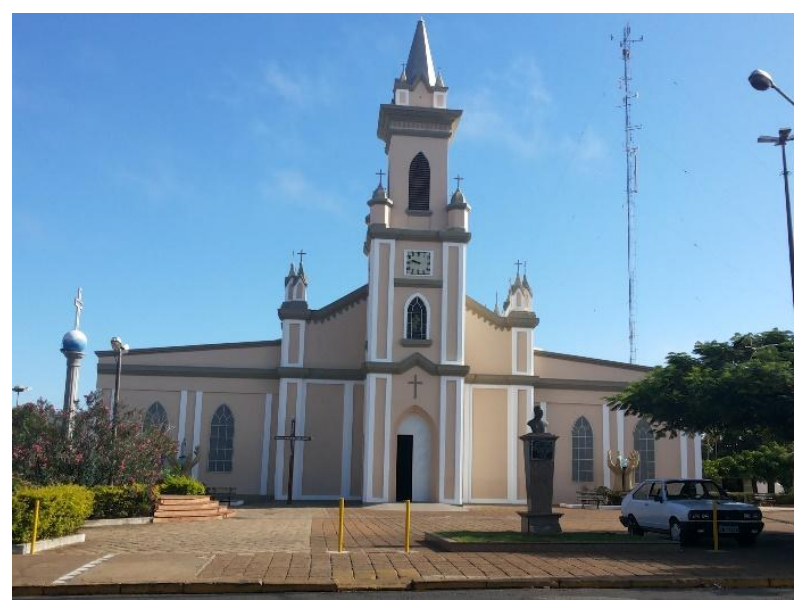

Figura 05. Fachada Atual

Fonte: Equipe 2015

A matriz tem vários elementos com referência ao Gótico pelos detalhes das janelas e portas, Renascimento por conter um pequeno frontão, art'Deco pelos detalhes escalonado do edifício. Por isso entende-se que seu estilo é eclético de 1946.

\section{CONCLUSÃO}

Esta edificação tem um grande significado social e religioso para a população de Pirapozinho. Esse vínculo inicia desde a construção da primeira capela à construção da Igreja Matriz com o envolvimento de toda a comunidade na ação contribuindo com doações de materiais, a disposição de trabalhar na construção em si. A igreja como a morada de Deus sempre foi um local de encontro para realização das orações e celebrações religiosas, sendo considerada por seus fiéis um lugar sagrado. Pois assim como a edificação é de suma importância os rituais religiosos que ali acontecem também são, formando um conjunto de história e memória por todos que ali realizaram seus casamentos, batismos, crismas, primeira eucaristia, além de todas as missas que foram realizadas durante toda sua história e que compõe a vinda e união de todos os fiéis para transformá-la na edificação hoje existente.

Dessa forma a importância que a Igreja Matriz representa a comunidade e também a cidade requer a importância de patrimônio cultural, que assim como citado acima por Martins (2011), "Património cultural é o conjunto de bens, materiais e imateriais, que são considerados de interesse coletivo, suficientemente relevantes para a perpetuação no tempo", a história dessa edificação nunca pode ser apagada no tempo, eliminando todas as memórias que aquele lugar guarda, e assim se explica a grande importância do tombamento que preserva e mantém a obra com todas suas características reais, impedido descaracterização ou destruição da edificação que 
reflete diretamente na vida, história e memória de cada um de seus fiéis e das futuras gerações que não terão conhecimento da história e dos "Por que?" de muitas ações.

\section{REFERÊNCIAS}

ARENDT, Hannah. Entre o passado e o futuro. 2a ed. São Paulo: Perspectiva, 1979.

DONIZETE, Rodrigues. Patrimonio cultural, Memória social e Identidade: Uma abordagem antropológica.

MARTINS, Sara D. Teixeira (2011). A Memória de um Lugar: discursos e práticas identitárias na Freguesia do Castelo em Lisboa. Dissertação de mestrado em Antropologia. ISCSP/ Universidade Técnica de Lisboa.

MIRANDA, Marcos Paulo de Souza. 0 inventário como instrumento constitucional de proteção ao patrimônio cultural brasileiro. Disponivel em: <http://jus.com.br/artigos/11164/o-inventariocomo-instrumento-constitucional-de-protecao-ao-patrimonio-cultural-brasileiro>. Acesso em 08 de Agosto de 2015.

Secretaria Casa Paroquial, Pirapozinho - SP. Visitado em 25 de maio de 2015. 